\title{
University Library Internet WeChat Public Account Applicated for Student Values
}

\section{Education}

\author{
Yan Zhao \\ General Education Center \\ Xi'an Peihua University \\ Xi'an, China \\ e-mail: qianyanzhao@yeah.net
}

\begin{abstract}
With the popularization of intelligent mobile phoness, mobile phones instant messaging application has achieved rapid development, at the same time, along with the SNS (Social Network Service) development, combined with mobile phones instant messaging and SNS has become an important means of the current Internet environment for people to communicate, in this trend, the university library is constantly looking for every kind of platform the expansion of information service. WeChat is a public platform for multimedia service platform Tencent Inc launched in the WeChat foundation, since August 2012 officially launched, quickly applied to restaurants, hotels, banks and other industries, and achieved good development, University library also actively use WeChat public platform, a new method to create the information service. In September 4, 2012, Beihang University opened a WeChat public platform, the first university library and university library, China also launched WeChat service platform, designed for teachers and students to provide more convenient and fast, and various information services, among them, China"985" universities, public service platform of WeChat has 30 colleges and universities the library opened the official certification, the "985" university libraries provide public service platform of WeChat earlier, in the function of the platform construction experience is relatively rich, ahead of other colleges and universities in china. Investigation and analysis of the public use of the WeChat, and on the construction of college students, some university libraries in $\mathrm{Xi}$ 'an city to carry out the use of WeChat, the public number, in order to understand the Xi'an City University library with the WeChat platform opened the public service teaching situation through research, especially the university library using the WeChat public number of value education, to some experience through investigation of University library in this aspect, also hope to find some problems, and put forward the Countermeasures of university library with the educational values of college students network of new media services.
\end{abstract}

Keywords-University Library; WeChat Public Account; Values Education

\section{INTRODUCTION}

With China's entry into the new era of mobile Internet, WeChat and other new media technologies are developing rapidly. Social culture and consciousness show some new characteristics of multiple integration and changeable conflicts. Values education for college students are important. The university library may play an important role of university education. University culture and knowledge base of the harbor, the cultivation of college student values promotion has a natural advantage and responsibility. The university library by using new technology and new network digital network equipment is for students' value guidance, education is in line with the characteristics of practice.

In this paper, WeChat public platform of University library were compared. Some colleges and universities on the library of Xi'an city by the WeChat platform launched a public account for the status quo and the values education of college students using the WeChat public situation of investigation and analysis, I hope some experience through summing up the University library in this aspect, also hope to find some problems in thus, this paper proposes that university libraries in the use of new media network services in the education of values of college students countermeasures.

Based on a comprehensive survey method, combined with questionnaire survey, this paper investigates and statistics the opening, accreditation, service function, number of tweets, tweets, publicity and promotion mode, and the use of WeChat public account of more than 10 public libraries in Xi'an. 


\section{ANALYSIS OF WECHAT PUBLIC ACCOUNT OF UNIVERSITY LIBRARY IN XI'AN}

\section{A. Xi'an University library WeChat public account} construction and development status

By the end of 2017, all the university libraries in Xi'an had opened the WeChat public account, including Northwestern Polytechnical University library, Shaanxi Normal University library and Chang'an University library as subscription numbers, and others as service numbers. The library of Xi'an Jiao Tong University was opened in July 2013. It is the first university in Xi'an to open WeChat public account. Northwestern Polytechnical University, Northwestern University and Xi'an Electronic and Science University were launched in March 2015, July and 11, accounting for $42.8 \%$. The opening time of Northwest Agriculture and Forestry University, Shaanxi Normal University and Xi'an Peihua University was in June 2016, October and November, accounting for $28.6 \%$ of the proportion.

1) Analysis of the service content of the WeChat public account in the university library of Xi'an

According to the author's investigation, the WeChat public account in most university libraries provides a custom content service. The public library WeChat set custom menu options according to their own characteristics, custom content retrieval service covers the lending service to provide a collection of query, retrieval, borrow, and continued (borrow), booking books and other services; information push service, including the announcement of the news, switching time and other services; reading promotion service including the book recommendation, collection, distribution, online bookstore, book recommendation; the library service, including training room / seat reservation, borrowing rules, common problems, card services, contact us. Chang'an University library, WeChat public provide extension services to the lost and found; WeChat Public Library of Northwestern University, the China Institute Library will also guide new service in the custom menu, easy to understand the use of new library services and resources.
In the library of WeChat public service mode, Xi'an Jiao Tong University, Northwest Agriculture and Forestry University, Northwestern Polytechnical University, Northwestern University, 4 university libraries provide self-service WeChat public consultation, including Northwest Agriculture and Forestry University, Northwestern Polytechnical University library for the user, the system reply all numbers with the keywords, users need to reply system provided by the number or keyword library related service regulations. The library system of Xi'an Jiao Tong University and Northwestern University reverted to the way of searching and querying, WeChat binding and other contents. The library also provided QQ and telephones contact. Xi'an Electronic and Science University library provides similar real-time interactive consultation, according to user questions to extract keywords, keyword answer system based on user consultation, the content of the answer is still several digital options or search keywords, only on the relatively detailed answer, targeted and relatively higher specificity. However, there is a response deviation caused by inaccurate keyword extraction, which is still unable to meet the user's personalized consultation demand. The WeChat public account of the Shaanxi Normal University and the Chang'an University library has not provided consulting services. The Xi'an Peihua University is more specific to push the new book appreciation.

2) Analysis of the service content of the WeChat public account in the university library

According to the author's investigation, the WeChat public account in most university libraries provides a custom content service. The public library WeChat set custom menu options according to their own characteristics, custom content retrieval service covers the lending service to provide a collection of query, retrieval, borrow, and continued (borrow), booking books and other services; information push service, including the announcement of the news, switching time and other services; reading promotion service including the book recommendation, collection, distribution, online bookstore, book recommendation; the library service, including training room / seat reservation, borrowing rules, common problems, card services, contact us. Chang'an University library, WeChat public provide 
extension services to the lost and found; WeChat Public Library of Northwestern University, the China Institute Library will also guide new service in the custom menu, easy to understand the use of new library services and resources.

In the library of WeChat public service mode, Xi'an Jiao Tong University, Northwest Agriculture and Forestry University, Northwestern Polytechnical University, Northwestern University, 4 university libraries provide self-service WeChat public consultation, including Northwest Agriculture and Forestry University, Northwestern Polytechnical University library for the user, the system reply all numbers with the keywords, users need to reply system provided by the number or keyword library related service regulations. The library system of Xi'an Jiao Tong University and Northwestern University reverted to the way of searching and querying, WeChat binding and other contents. The library also provided QQ and telephones contact. Xi'an Electronic and Science University library provides similar real-time interactive consultation, according to user questions to extract keywords, keyword answer system based on user consultation, the content of the answer is still several digital options or search keywords, only on the relatively detailed answer, targeted and relatively higher specificity. However, there is a response deviation caused by inaccurate keyword extraction, which is still unable to meet the user's personalized consultation demand. The WeChat public account of the Shaanxi Normal University and the Chang'an University library has not provided consulting services. The Xi'an Peihua University is more specific to push the new book appreciation.

\section{B. Analysis use of university library WeChat public account in Xi'an}

In 2017 10-12, the author conducted a survey of 10 colleges in Xi'an City, mainly adopts the simple random sampling method, the questionnaire and the use of the public library, WeChat exchange students from 10 universities, mainly college students basic information, the use of WeChat, WeChat, the public library and the public library on WeChat push the contents of investigation on College Students' values influence. A total of 460 questionnaires,
448 valid questionnaires, the questionnaire response rate was $97.39 \%$, analysis of the survey results can be seen the basic characteristics of the subjects of this research, the professional grade, a relatively balanced ratio of respondents mainly to undergraduate students (90.8), the use of WeChat for more than a year accounted for $87.5 \%$ of the respondents, compared with a representative sample.

According to the survey can be found in the library using the WeChat platform, students use the library to understand the WeChat public school/library events accounted for $67.9 \%$, accounted for $60.9 \%$ of the educational resources, access to bibliography, broaden the vision of college students accounted for $37.3 \%$ and $36.8 \%$ using the library WeChat platform, and $20.5 \%$ of students choose entertainment / send time. More than half of the college students used the library WeChat platform to pay attention to $68.1 \%, 67.4 \%$ and $62.7 \%$ of leisure, education and social life respectively. Through the library WeChat platform, concerned about current affairs politics, literature education, science and technology experiment, the number of college students who want to be enlightened is also a few, accounting for $43.8 \%, 40.4 \%$ and $32.1 \%$ respectively.

If the Reading Library WeChat platform push on values to enhance bibliographies and tweets, $48 \%$ of respondents choose around here, choose carefully accounted for $10.5 \%$, $29.2 \%$ of respondents said they would see the mood at that time, only 3.6 of respondents said they would not read. To evaluate the function of WeChat library platform, $72 \%$ person feels it is useful; $17 \%$ feels it is just common and $11 \%$ feels it is lack of information, shown as Figure 1.

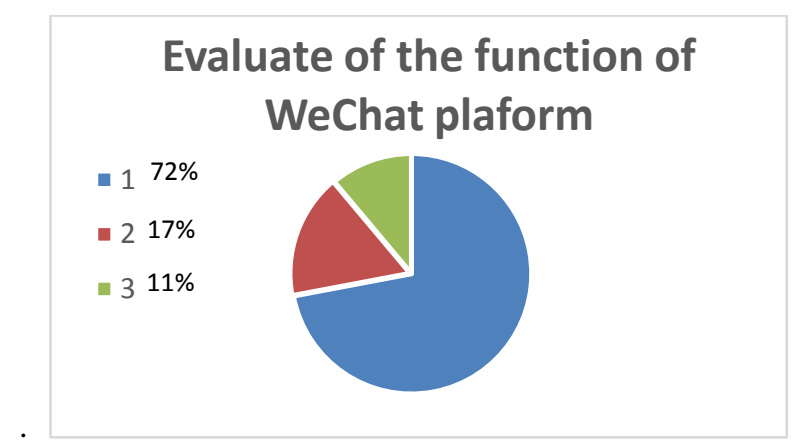

Figure 1. Evaluate of the function of WeChat platform in university library 


\section{SOME ISSUES NEED TO BE SOLVED}

\section{A. The university library is not enough to push the WeChat} public account.

"How to get the WeChat public platform information" in the school library, the teachers and students to recommend the most, accounting for $46 \%$, accounting for $44.2 \%$ of the school website, the library publicity activities and library websites / micro-blog recommended were accounted for $43.1 \%$ and $36.2 \%$, issued a notice on the counselor accounted for $13.8 \%$.

\section{B. The service content of the university library's WeChat public is not rich.}

Library's use of public account tweets content is also mainly based on database / resource usage instructions, lecture announcements and bulletin boards. The publicity of values is done more through the aspects of "good books to read" and other columns. At present, the WeChat public account of the university library is very few in the ideological and political education.

\section{The role of the WeChat public in values education is not outstanding.}

College students are willing to read and accept the library WeChat push bibliography and information; at the same time the push type indirect spread of values such as education, practice on paper than direct Indoctrination Theory on the propaganda more easily lead to college students' interest; subject of humor use network language more tweets get relatively more praise.

\section{COUNTERMEASURES OF WECHAT PUBLIC ACCOUNT} FOR COLLEGE STUDENTS VALUES EDUCATION

\section{A. Tobuild the public account of the university library with the characteristic brand}

Make full use of the advantages of WeChat university library, tap their own resources to develop new forms of the carrier, the use of written language expression, affinity rich content, the integration of existing services and tweets, build long-term push has a certain reputation tweets than columns, such as to improve the integration of the existing WeChat public account in various "recommended read" column, launched 1-2 columns, the number of monthly / weekly push without too much, with the tweets of high quality, the cultivation of College Students' values imperceptibly.

\section{B. Integrate the existing resources of the WeChat public account}

At present, the WeChat public account of the university library has very little content to carry out the ideological and political education propaganda values. Can fully tap the school history, famous expert deeds red resources, the integration of the existing school characteristic resources, strengthen propaganda guidance will dig out late, the red school history, advanced people inside and outside the school to fully display the true story, making the core values of the mainstream display platform, so that students in the true story of people around the infection through the positive publicity, enhance the value of deeper understanding.

\section{Set up a professional WeChat operation team to improve the quality of service}

The routine work of University library in the guarantee of quality of service at the same time, can build up a professional operations team in the WeChat Museum, invited the expert teachers of Humanities and Social Sciences, psychology guidance for students' reading psychology, tweets from the form, title, text, content and other aspects of design, will Chinese excellent traditional culture classics, humanities and Social Sciences classics, Chinese characteristic socialism theory system and so on, has positive energy culture beneficial things for transformation of the values of college students, can attract readers in content and form.

\section{Ensure line and line coordination}

In the WeChat online promotion at the same time, the relevant line museum activities cannot be a mere formality, WeChat promotion is just the first step, the library should be more careful to do online follow-up activities, and will continue to carry out follow-up posted on the WeChat public account, do detailed introduction to launch activities, release moments, released a wonderful message the activity, knowledge contest, increase the positive ideological and political education interest, improve students through the activities of attention participation, so that WeChat can 
achieve promotion effectively, improve college students' values.

\section{CONCLUSION}

In conclusion, the current Shaanxi university library is developing the library's traditional business on the platform of WeChat public. Meanwhile, it has opened various uses of WeChat public number, such as publicizing good books, communication between teachers and students, and values education for college students. From the current application and development situation, the overall service situation is optimistic, but based on the University library in the school environment and humanistic values of college students in the cultivation of special status, and the current WeChat is still in continuous development, technology also change rapidly, more powerful, so that university library should adapt to the development trend of the times, change under the new media environment of the service concept, make full use of WeChat to improve its service, strengthen the propaganda, improve the content, enhance students' sense of identity for the school, improve the school connotation and visibility, the public library, WeChat really serve in the mainstream platform of values education.

\section{REFERENCES}

[1] Liu Jing, China's University library certification user micro-blog investigation and analysis - Sina micro-blog as the platform [J], the library Study, 2012 (01):90-95

[2] $\mathrm{Hu}$ Xuanzhen university library, micro-blog fine service of [J], library work and study, 2014 (04): 36-38

[3] Kong Yun, Library Mobile Information Service Research Based on WeChat public account [J], information magazine, 2013 (9): 167-171

[4] Ye Haizhi, and [J], mobile information service of the library based on the design of the WeChat software guide, 2013 (11): 88-90

[5] Han adorable, development of information service by WeChat public platform of University library on [J], Library Journal, 2014 (10):111-115

[6] Shayne Bowman, Chris Willis, We Media-How audience are shaping the future of News and information[M], The Media Center, 2003, 6

[7] Zhang Yihan. University library to carry out WeChat service exploration [J]. modern business industry, 2015 (7): 92-93

[8] Qiu Yubing. Micro media era college library resources promotion -a case study of WeChat [J]. service as an example of Henan Library Journal, 2015 (4): 38-40

[9] Yang Rongrong. The investigation and analysis of the digital reference service in University library and Its Development Countermeasures -- taking 100 national exemplary university libraries as an example, [J]. library research, 2015 (2): 97-101 